\title{
Da leitura à reescrita: propostas e percursos da pedagogia baseada em gêneros
}

\author{
Luís Filipe Barbeiro ${ }^{1}$ \\ ORCID: 0000-0001-5798-2904
}

\section{Resumo}

0 presente estudo incide sobre a estratégia de reescrita de outro texto, enquanto instrumento promotor da aprendizagem da própria escrita. Tem como objetivo contribuir para o conhecimento das potencialidades e limitações de diferentes estratégias para estabelecer a relação entre a leitura e a escrita, por meio da reescrita. 0 estudo coloca em foco uma estratégia específica, integrada na pedagogia baseada em gêneros ou pedagogia de base genológica. Esta perspectiva atribui à leitura e à reescrita a partir de outros textos um papel fundamental para a aprendizagem da escrita. 0 presente estudo analisa a reescrita de textos narrativos por alunos do $5^{\circ}$ e $6^{\circ}$ anos de escolaridade, realizada no âmbito do programa de base genológica Reading to Learn (Ler para Aprender), em comparação com a reescrita dos mesmos textos por alunos que não participaram no programa. Os resultados mostram um contraste significativo entre os dois grupos. Este manifesta-se por um maior nível de especificidade nos textos reescritos pelos alunos participantes no programa. No caso dos restantes alunos, as reescritas adotam uma maior generalização, pautada pela sucessão dos eventos mais marcantes do fio narrativo. A conclusão e implicações apontam para a necessidade de não limitar a reescrita a esse fluxo narrativo, mas de instruir os alunos para possibilidades que promovam a apropriação dos recursos léxico-gramaticais.

\section{Palavras-chave}

Leitura - Escrita - Pedagogia de base genológica - Reescrita.

1- Instituto Politécnico de Leiria, Escola Superior de Educação e Ciências Sociais, Leiria / Centro de Estudos de Linguística Geral e Aplicada (CELGA-ILTEC), Universidade de Coimbra, Coimbra, Portugal. Contato: luis.barbeiro@ipleiria.pt. 


\section{From reading to rewriting: proposals and strategies of genre-based pedagogy}

\section{Abstract}

The present study focuses on the strategy of rewriting as an instrument to support pupils as they learn how to write well. It aims to contribute to our knowledge of the potential and the limitations of various strategies, all of which involving the activity of rewriting, that establish a relationship between reading and writing. The study focuses on one specific strategy, arising from genre-based pedagogy. In this approach, reading and rewriting other texts, taken as models, play a key role in learning how to write. The current study analyses the rewriting of narrative texts by fifth and sixth graders. More specifically, it analyses rewritings produced by the participants in the genre-based Reading to Learn programme, comparing them with rewritings of the same texts by students who did not participate in the programme. The results show a significant contrast between the two groups. The contrast is manifested in a higher level of specificity in the texts rewritten by the students participating in the programme. With regard to the other students, the rewritings reveal a higher degree of generalization, characterized by a series of the most striking events in the narrative thread. The article concludes that it is not necessary to restrain text rewriting to the narrative flow but rather to increase students' consciousness of the opportunities that promote the appropriation of lexical-grammatical resources.

\section{Keywords}

Reading - Writing - Genre-based pedagogy - Rewriting.

\section{Introdução}

A reescrita constitui uma força duplamente poderosa para a própria atividade de escrita. Por um lado, essa força pode advir do dinamismo que o prefixo re-desencadeia, no próprio processo de escrita, por meio da recursividade. Por outro lado, pode advir da possibilidade de recriar, tendo por base um produto já existente.

As duas vertentes têm estado presentes no ensino da escrita. A primeira, recursiva, adquiriu relevo nas últimas décadas associada às teorias e modelos processuais (HAYES; FLOWER, 1980; EMIG, 1983; BEREITER; SCARDAMALIA, 1987; HAYES, 1996, 2012). A segunda, recriativa, encontra raízes no ensino da escrita, a partir de obras literárias consagradas que servem de modelos (FONSECA, 1990). Esta perspectiva ganhou novo impulso ao ocupar o espaço deixado vago pelas perspectivas processuais em relação à construção social do significado (HYLAND, 2003; MARTIN; ROSE, 2008; ROSE; MARTIN, 2012; HALLIDAY; MATTHIESEN, 2014; ROSE, 2015, 2016a). É no âmbito desta segunda 
vertente, enquadrado pela pedagogia de base genológica proposta pela escola de Sydney (MARTIN; ROSE, 2008; ROSE; MARTIN, 2012) que se integra o estudo apresentado.

0 estudo tem como objetivo apreender potencialidades de uma modalidade de reescrita, concretizada no âmbito da aplicação do programa Reading to Learn (Ler para Aprender). Este programa consubstancia as propostas da escola de Sydney em relação ao ensino da leitura e escrita, segundo uma perspectiva genológica (ROSE; MARTIN, 2012; ROSE, 2012, 2016a).

As atividades levadas a cabo na aula constituem uma dimensão importante do contexto pedagógico e, em combinação com as relações pedagógicas e com os modos ativados para a significação, integram as possibilidades à disposição do professor para a construção de conhecimento e de valores (ROSE, 2018a). 0 estudo de formatos específicos de concretização de atividades em contexto pedagógico, como acontece neste estudo, promove a fundamentação consciente das escolhas e a delimitação das potencialidades que oferecem.

\section{Enquadramento conceitual}

\section{Reescrita e potencial catalisador na aprendizagem}

A construção social do significado através da linguagem é realizada por textos. 0 texto constitui uma unidade ao serviço de propósitos sociocomunicativos, ou seja, de construção do significado num contexto (HALLIDAY; MATTHIESEN, 2014). 0 processo de produção textual é marcado por escolhas para alcançar esses propósitos. Essas escolhas podem consistir na ativação inconsciente de possibilidades facultadas pelo sistema (HALLIDAY, 2013), mas também podem emergir de forma consciente (O'DONNEL, 2013). 0 percurso de aprendizagem da escrita é, em grande medida, um percurso de alargamento da capacidade de realizar escolhas para a construção do texto. A reescrita constitui uma estratégia que coloca em foco as escolhas para serem alcançados em maior grau os objetivos sociocomunicativos.

As duas abordagens referidas em relação à atividade de reescrita constituem estratégias adotadas para o desenvolvimento do processo criativo e podem, também, ser trazidas para o processo pedagógico, com o objetivo de desenvolver o domínio da escrita. A abordagem que toma a reescrita no interior do processo procura uma versão melhorada do texto, em resultado da revisão (LEGROS et al., 2006; FIAD; BARROS, 2013; FERREIRA; ARAÚJO, 2014; SARTORI; MENDES, 2016). A abordagem correspondente à tomada de um texto-produto como referência parte desse texto para inovar ou para o tomar como modelo. 0 novo produto pode ser mais ou menos personalizado, mais ou menos próximo ou afastado do texto original, podendo retomar estruturas textuais e também recursos linguísticos ou de conteúdo, também com o objetivo de serem apreendidos pelos alunos (COSTA et al., 2010; ROSE, 2012, 2018b; ROSE; MARTIN, 2012; BARBEIRO, 2016). Assinalamos, para a primeira abordagem, a ligação à perspectiva processual e, para a segunda, a ligação à perspectiva genológica. 
0 programa Ler para Aprender, situado na perspectiva genológica, atribui à leitura de textos de um determinado gênero um papel basilar para a aprendizagem da escrita de textos desse mesmo gênero (ROSE, 2012, 2016a, 2018b; ROSE; MARTIN, 2012; GOUVEIA, 2014). Com vista a que a apropriação tenha lugar, ao lado da leitura, a reescrita ocupa um lugar fundamental.

A estratégia de reescrita, juntamente com outras, pretende ter um efeito catalisador, ou seja, acelerar conquistas a partir das potencialidades da leitura. Estas conquistas demorariam mais tempo, se tivessem por base apenas a participação em experiências de literacia, impregnando ou construindo, como que por osmose, as competências dos alunos, ou dependendo das suas próprias descobertas. Os catalisadores tornam-se sobretudo necessários em relação aos alunos que não puderam contar, ao longo da sua infância, com as experiências de literacia que dão acesso ao conhecimento sobre a escrita e ao conhecimento que a linguagem escrita, nos seus diferentes gêneros, veicula (ROSE, 2016b). Adams (1990) e Williams $(1995,1999)$ realçam a importância, mas também a quantidade de horas de experiências de literacia partilhadas com as crianças, em contextos familiares letrados.

Quando esta quantidade de experiências de literacia já existe, à chegada à escola, e acompanhando a criança no seu percurso escolar, a tarefa da escola encontra-se facilitada (ROSE; MARTIN, 2012, ROSE, 2016b). 0 desafio que se lhe coloca consiste em potenciar esse conhecimento e, sobretudo, em permitir às crianças que não tiveram acesso as essas vivências instrumentos para alcançarem níveis semelhantes de sucesso em relação aos seus colegas que podem basear nessas experiências a sua aprendizagem. Por isso, tornase relevante encontrar catalisadores que acelerem a construção da relação com os textos.

A reescrita constitui um desses potenciais catalisadores, mas também coloca desafios. Entre as potencialidades, podemos referir as mais-valias apontadas por Costa e colaboradores (2010), como resposta à pergunta sobre se a reescrita de outro texto, designadamente o reconto enquanto prática de escrita regular, não será uma prática improdutiva e pouco estimulante. As autoras apresentam a posição seguinte:

Não, se a encaramos como situação de escrita com uma dupla mais-valia: por um lado, a apropriação de recursos linguísticos novos, de registos discursivos alheios, de estratégias comunicativas desconhecidas e, ao mesmo tempo, oportunidade de criação própria. 0 reconto pode dar margem para criar, por isso pode dar prazer, fazendo aprender. (COSTA et al., 2010, p. 112).

As autoras sintetizam a sua posição considerando que "o contributo do reconto como estratégia de ensino consiste, em particular, na disponibilização de um modelo textual e de elementos discursivos novos" (COSTA et al., 2010, p. 114). A existência de um texto-modelo reflete-se, de forma saliente, na estrutura do gênero de que o texto original é um representante ou espécime (HALLIDAY; MATTHIESSEN, 2014) e que, de forma muito frequente, serve de armação para o texto que é reescrito. Os elementos discursivos novos podem ser vistos numa dupla perspectiva. Do ponto de vista do discurso do sujeito, como apontam Costa e colaboradores (2010), são elementos novos, disponibilizados pelo texto, de que o sujeito se pode apropriar, integrando-os no seu discurso. Do ponto de vista do produto, a reescrita, podendo ser uma imitação, não é uma cópia do texto-modelo, 
como Santos e colaboradores (1998) realçam, em consonância com Teberosky (1996). Por conseguinte, não sendo a versão reescrita uma cópia, o sujeito traz alguma coisa de novo ou retira algo em relação ao texto original, enquanto outros elementos permanecerão no texto recriado - "haverá esquecimentos e modificações, mas também aspectos do texto original serão mantidos” (SANTOS et al., 1998, p. 214).

Do ângulo focado no produto reescrito, surge o desafio de os contributos, as modificações ou elementos novos, trazidos pelo sujeito para a reescrita, constituírem no processo e no novo produto uma mais-valia para essa aprendizagem, ou seja, não constituírem um rebaixamento, uma redução em relação aos objetivos a alcançar. A resposta a esse desafio implica um trabalho pedagógico específico. Esse trabalho pode ser desenvolvido a anteceder a reescrita de cada sujeito (por exemplo, como veremos a seguir, através da Leitura Detalhada e da Reescrita Conjunta no programa Ler para Aprender - ROSE, 2012; ROSE; MARTIN, 2012); ou a acompanhá-la, por exemplo, através de orientações específicas para a realização da tarefa de reescrita e através do acompanhamento do professor (COSTA et al., 2010).

Uma das potencialidades da reescrita de um texto tomado como modelo é precisamente libertar o sujeito de algumas tarefas implicadas pela escrita compositiva. Já nos referimos à estrutura, geralmente retomada (ou, pelo menos, tomada como referência, no caso de haver modificações). A retoma pode estender-se a outros domínios, como a geração e seleção de ideias ou conteúdo, pois este pode ser disponibilizado, em maior ou menor grau, pelo texto a reescrever. Facilita-se, deste modo, a tarefa de escrita no percurso de desenvolvimento (em consonância com a estratégia de facilitação processual proposta por Bereiter e Scardamalia, 1987). Possibilita-se que o aprendente se foque na escolha dos elementos discursivos que podem ser mobilizados na reescrita do texto. Esta dimensão facilitadora da reescrita em relação a aspectos de conteúdo é salientada por Santos e colaboradores (1998), a partir do expresso por Teberosky (1996): "facilitamos a seleção de idéias para conseguir que as crianças possam se ocupar do escrever do ponto de vista da composição e da colocação no seu formato gráfico" (SANTOS et al., 1998, p. 215, grifos dos autores).

A reescrita ao nível discursivo pode estar orientada segundo duas metas diferentes, associadas a dois tipos diferentes de texto (ROSE, 2012; ROSE; ACEVED0, 2017). Nos textos que têm como objetivo sociocomunicativo envolver o leitor, como as histórias, o desafio é escrever um novo texto do mesmo gênero, segundo o modelo estrutural e os recursos ou padrões de linguagem que mantenham o nível de elaboração do texto original, para que esse objetivo continue a ser alcançado. Em relação aos textos factuais, como os expositivos e informativos, o objetivo da reescrita é apresentar o mesmo conteúdo com recurso a uma linguagem mais próxima da compreensão do aluno. Assim, o desafio da reescrita será tornar o aluno capaz de, sem repetir o texto original, apresentar a informação por meio de paráfrase, num discurso de que ele próprio é sujeito, que ele próprio é capaz de construir, continuando a ter presente o desafio de rigor que deverá ter encontrado no texto original.

Apesar do reconhecimento das potencialidades da reescrita, designadamente no âmbito da pedagogia de base genológica, a investigação não aprofundou a análise de potencialidades em relação a diferentes formatos para as levar à prática. 0 que é 
disponibilizado pela literatura (ROSE, 2012, 2018b; ROSE; MARTIN, 2012; ROSE; ACEVEDO, 2017) consiste fundamentalmente em exemplificações da condução das atividades e das produções realizadas pelos alunos. Fazem falta análises sistemáticas e alargadas das produções escritas (reescritas) que a atividade de reescrita, segundo determinado formato, permitiu alcançar, num contexto de prática. No estudo que apresentamos, procedeu-se à análise das reescritas dos alunos das turmas de uma escola envolvidas na aplicação do programa Ler para Aprender, em contraste com reescritas dos alunos de turmas que não participavam no programa.

\section{Atividades do programa Ler para Aprender em foco no estudo}

Referimo-nos anteriormente ao trabalho pedagógico necessário para manter na reescrita os padrões ou níveis de elaboração e sofisticação linguísticas encontrados no texto original ou para expressar o conteúdo dos textos factuais, segundo novo discurso, correspondente à assunção do conhecimento por parte do aluno. 0 trabalho pedagógico proposto pelo programa Ler para Aprender desenvolve-se segundo três níveis ou ciclos de atividades (ROSE, 2012; ROSE; MARTIN, 2012; ROSE; ACEVEDO, 2017):

- o nível mais geral, ou ciclo externo, inclui as atividades de preparação para a leitura, construção conjunta (de um texto do mesmo gênero, apoiada no modelo encontrado), as quais servem de apoio para o aluno conseguir alcançar a construção autônoma desse gênero de textos;

- o segundo nível, ou ciclo intermédio, incide sobre passagens mais específicas como parágrafos ou conjuntos de parágrafos dotados de alguma unidade e reforça a explicitação de estruturas léxico-gramaticais de que o texto se serve para construir o significado; essas estruturas são focadas na leitura detalhada e o trabalho realizado sobre elas projeta-se na reescrita conjunta da passagem e, depois, na reescrita individual;

- o terceiro nível, ou ciclo interno, coloca em ação um trabalho sobre as unidades situadas na base da construção do texto, como as frases e as palavras; inclui atividades de manipulação de frases, de ortografia e de escrita de frases.

As atividades que estiveram em relevo no trabalho pedagógico envolvente do presente estudo foram sobretudo a preparação para a leitura, no ciclo externo, e as atividades do ciclo intermédio (leitura detalhada, reescrita conjunta e reescrita individual).

A preparação para a leitura procura assegurar que, no momento da realização da leitura, todos os alunos consigam alcançar um nível elevado de compreensão. Para isso, o professor antecipa o texto, quer em relação à sua estrutura, quer em relação ao conteúdo e recursos linguísticos mais salientes que os alunos irão encontrar. Quando a leitura tem lugar, os alunos têm a oportunidade de confirmar o que já foi revelado em relação ao texto, evitando que fiquem perdidos na procura da sua compreensão. A própria leitura de cada parágrafo ou bloco textual pode ser antecedida do ato de reavivar ou de complementar o que foi dito na atividade inicial da preparação para a leitura. Para esta preparação, o 
professor pode ainda chamar e ativar o conhecimento que os alunos têm em relação ao campo e ao gênero do texto.

Já no nível intermédio, a leitura detalhada tem como objetivo levar os alunos a alcançar uma compreensão aprofundada, assente na explicitação dos recursos linguísticos que foram escolhidos para o texto. Os alunos são colocados perante o desafio de identificarem e realçarem palavras e expressões, a partir da explicitação do seu valor semântico ou da sua posição na frase. A sua colocação em foco, a explicitação do seu funcionamento no texto e a expansão do conhecimento por relação com outras palavras e expressões tem como objetivo que os alunos passem a dominar essas palavras e expressões ou aquelas encontradas no percurso de elaboração/aprofundamento do conhecimento, a fim de as integrarem nos seus textos.

Essa oportunidade de integração das palavras e expressões encontradas na passagem e na elaboração realizada a partir dela surge logo com a reescrita conjunta. Nesta atividade, os alunos são guiados pelo professor na tarefa de reescrita, antes de a praticarem sozinhos na reescrita individual. Ao chegarem à reescrita individual, os alunos já podem apoiar-se no trabalho pedagógico realizado nas atividades anteriores e nos recursos linguísticos aí colocados em foco e explicitados. Através da reescrita, pretende-se que os alunos se apropriem desses recursos, "mantendo os padrões sofisticados de linguagem de um texto literário, ou o nível de especificação e rigor de um texto factual" (ROSE, 2012, p. 4). 0 objetivo final é que o aluno seja capaz de integrar esses recursos nos seus próprios textos. A reescrita constitui, assim, uma etapa intermédia de manejo dos recursos linguístico-textuais associados a determinado gênero.

A importância do papel do professor emerge por meio da explicitação dos recursos e das atividades conjuntas (reescrita conjunta e construção conjunta) e está no cerne do próprio programa. 0 professor suscita, guia e participa ativamente nas atividades atribuindo igualmente um papel ativo aos alunos, em conformidade com o princípio de "orientação através de interação no contexto de experiência partilhada", formulado por Martin (1999, p. 126, grifos nossos). Este princípio remete para a progressão na aprendizagem possibilitada por meio da ajuda na zona de desenvolvimento proximal, segundo a perspectiva vygotskyana (VYGOTSKY, 1991).

Como referido, para a estratégia de reescrita, o programa Ler para Aprender estabelece um procedimento diferente entre os textos integrados no gênero histórias e os textos factuais. Para as histórias, o programa propõe a reescrita de uma nova história, que reutilize os mesmos padrões de linguagem, mas com novo conteúdo, ou seja, um novo campo (ROSE, 2012; ROSE; ACEVED0, 2017). Para os textos factuais, o programa propõe a reescrita do mesmo conteúdo, ou seja, o mesmo campo (tópico ou assunto), recorrendo-se a uma linguagem diferente, próxima da compreensão dos alunos, que foi trabalhada na atividade de leitura detalhada através da tomada de notas (ROSE, 2012; ROSE; ACEVED0, 2017).

Contudo, na sequência das potencialidades da reescrita para criar uma nova versão de um texto, apontadas por Costa e colaboradores (2010) também em relação a gêneros narrativos, podemos perguntar-nos se a atividade de reescrita não poderá incluir a modalidade de reescrita do mesmo texto, mantendo-se o respectivo campo 
ou tema. É a partir desta questão que surge o presente estudo, com a finalidade de apreender as potencialidades de reescrita de textos narrativos num patamar de maior proximidade, pela manutenção do campo, em relação ao texto original (BARBEIR0, 2016).

0 interesse em aprofundar a análise das potencialidades desta modalidade também em relação aos textos narrativos e de natureza literária surgiu pela dificuldade encontrada, na aplicação do programa, quando os alunos eram confrontados com o desafio de encontrar situações paralelas em que os recursos linguísticos encontrados no texto original pudessem ser aplicados. Essa dificuldade manifestou-se sobretudo quando estava em causa o estudo de obras literárias de leitura integral ou o trabalho sobre textos dos manuais (geralmente excertos de obras mais vastas) que não correspondiam de forma clara a gêneros específicos, mas que terão sido escolhidos para o manual por evidenciarem determinados recursos linguísticos com que se pretende que os alunos contatem. Na atividade de leitura detalhada, os alunos tiveram oportunidade de apreender esses recursos, de os associar a outros (sinônimos, paráfrases etc.) e às suas experiências de leitura e de vida, por meio da elaboração ou alargamento da aprendizagem. Na reescrita conjunta da mesma passagem, o alargamento de recursos pode continuar a ser feito, proporcionado pelo professor, que orienta a atividade e assegura a manutenção do nível de sofisticação linguística pretendido, mesmo com a ativação de novos recursos. Assim, quando chega o momento da reescrita individual, o aluno já dispõe de um conjunto de recursos, que aprendeu em ligação aos elementos presentes no texto original, e que poderá mobilizar na sua reescrita, selecionando entre eles ou outros os que quer utilizar na escrita de uma nova versão do texto/ excerto (BARBEIR0, 2015). Esta modalidade de reescrita pretende constituir um patamar intermédio de apoio à apropriação de recursos linguísticos, segundo o nível de sofisticação modelado por textos de qualidade reconhecida, que promova a sua reutilização nos textos do próprio aluno. 0 fato de nesta modalidade de reescrita 0 aluno contar com a facilitação processual (BEREITER; SCARDAMALIA, 1987) ou com o suporte ou andaime (scaffold, estabelecendo a ligação à perspectiva de Bruner, 1983) do tema ou campo e da estrutura, já delimitados e disponibilizados pelo texto original, pode promover que o foco seja direcionado precisamente para os recursos linguísticos, para a sua seleção de entre os encontrados ou para o alargamento da procura segundo os níveis de elaboração pretendidos. A questão que emerge é se, tendo o mesmo texto original como ponto de partida, as atividades desenvolvidas no âmbito do programa Ler para Aprender promovem a produção de textos reescritos substancialmente diferentes em relação a alunos não integrados no programa.

\section{Metodologia}

Do ponto de vista metodológico, é relevante ter em conta dois níveis: o nível geral, equivalente ao desenvolvimento do projeto ao longo do ano letivo, e o nível específico, constituído pelo estudo aqui apresentado, um recorte focado numa estratégia de reescrita. No nível geral, a integração dos professores no projeto implicou a 
participação numa formação, na modalidade de oficina. Esta modalidade intercalou sessões presenciais em grupo e períodos de desenvolvimento de prática pedagógica. Nas sessões presenciais conjuntas, incluíram-se a identificação e consciencialização dos problemas experienciados pelos professores no ensino da escrita, a procura de respostas para esses problemas mediada pelas propostas da pedagogia de base genológica, a reflexão sobre os resultados que iam sendo obtidos, formas de resolver os problemas encontrados e de promover a aprendizagem. A própria investigação, tal como a aqui apresentada, integrava o processo de reflexão. Neste sentido, o processo formativo aproximou-se da investigação-ação, apoiada pela interação no âmbito grupo formado pelos professores e os formadores.

Um dos problemas identificados e colocados em foco logo no início da oficina consistiu na dificuldade de se levar os alunos a estabelecerem a ligação entre a leitura e a escrita, isto é, se apropriarem dos recursos linguísticos encontrados nos textos lidos e trabalhados na aula. Este problema deu realce à estratégia de reescrita e fez surgir o estudo específico, de natureza constrastiva entre duas abordagens: a que vinha sendo habitualmente seguida na escola, focada na leitura e interpretação, e a que insere a reescrita no trabalho a partir de um texto.

\section{Instrumentos e estratégias pedagógicas}

0 estudo decorreu numa escola do $2^{\circ}$ ciclo do ensino básico, da região de Leiria, Portugal, em turmas do quinto e do sexto anos de escolaridade, na qual estava a ser desenvolvido o projeto TeL4ELE (Teacher Learning for European Literacy Education).

No quinto ano de escolaridade, o texto que serviu de base ao presente estudo foi o excerto de A floresta, de Sophia de Mello Breyner Andresen, correspondente ao encontro de Isabel com o anão. No sexto ano de escolaridade, foi trabalhado o excerto da obra Ulisses, de Maria Alberta Menéres, no qual é relatado o aparecimento da ideia e a construção do cavalo de madeira. 0 estudo destes excertos integrou-se na leitura mais alargada das respectivas obras.

As atividades do programa Ler para Aprender, em ligação a este estudo, postas em prática nas turmas em que foi aplicado foram a preparação para a leitura, seguida da leitura por blocos ou parágrafos dos textos em causa, a leitura detalhada, a reescrita conjunta e a reescrita individual, segundo a explicitação realizada na secção anterior. A leitura detalhada e reescritas individual e conjunta incidiram sobre os trechos apresentados nos Apêndices 1 e 2.

Nas turmas em que não foi aplicado o programa Ler para Aprender, a estratégia pedagógica consistiu na abordagem habitual de leitura do texto, seguida de questionário de compreensão, correção das respostas, esclarecimento de dúvidas e resolução de dificuldades de interpretação, para além de tratamento de aspectos gramaticais, ligados às unidades linguísticas do texto. Nesta abordagem, o foco estava colocado na leitura e interpretação da obra, sem fazer a ligação explícita com a escrita, excetuando a resposta por escrito a questões de interpretação, as quais implicavam, por vezes, a inserção da passagem no conjunto da obra. 


\section{Procedimentos}

A concretização do projeto TeL4ELE nas escolas envolvidas foi objeto de autorizações por parte do Ministério da Educação, das direções dos Agrupamentos, da escola de ensino superior que dinamizou o processo em cada núcleo e dos participantes nas atividades. Os professores aderiram de forma voluntária à participação no projeto e deram o seu consentimento esclarecido através de declaração assinada, para a recolha de dados (textuais, inquéritos por questionário e entrevista e também por meio de registos áudio e vídeo).

Como as atividades do programa se integravam nas aulas, os professores esclareceram os alunos quanto às atividades que iriam passar a dinamizar. Em relação aos alunos, a autorização para a recolha de dados, incluindo por meio de registo de som e imagem, foi obtida mediante declaração dos encarregados de educação. Para a obtenção desta declaração, foi enviada ao encarregado de educação de cada aluno uma síntese explicativa dos objetivos e metodologia do projeto, tendo os professores complementado a informação por ocasião da realização de reuniões e em contatos diretos com os encarregados de educação. Em relação aos alunos das turmas não participantes na aplicação do projeto, a autorização incluiu apenas a análise de produtos textuais. Para além dos professores, todos os encarregados de educação dos alunos contatados (e os próprios alunos) deram a sua autorização para a recolha de dados e respectiva análise para os fins investigativos e pedagógicos indicados.

No caso deste estudo, a recolha de dados incidiu nos textos reescritos. Essa recolha decorreu no quinto e no sexto anos de escolaridade. No quinto ano, envolveu quatro turmas; em duas, que passaremos a considerar como Grupo A ( $5^{\circ}$ ano), totalizando 44 alunos, estavam a ser aplicadas as atividades do programa Ler para Aprender; noutras duas, que passaremos a referir como Grupo B ( $5^{\circ}$ ano), estavam a ser aplicadas as atividades habitualmente levadas à prática, tendo sido recolhidos textos reescritos de trinta alunos (pois registaram-se algumas ausências na altura da realização da atividade). No sexto ano de escolaridade, foram recolhidos dados em três turmas integradas no programa Ler para Aprender (Grupo A, $6^{\circ}$ ano) totalizando 64 alunos, e em duas turmas que não participavam no programa, totalizando 35 alunos (Grupo B, $6^{\circ}$ ano). Participaram, em cada ano de escolaridade, turmas de duas professoras diferentes, quer nos Grupos A, de aplicação do programa, quer nos Grupos B.

As planificações das aulas integradas na aplicação do programa Ler para Aprender foram orientadas pelos formadores que dinamizavam a oficina de formação que acompanhava o projeto. As planificações das atividades realizadas nas turmas que não participaram no programa advinham de planificações realizadas em anos anteriores pelo grupo de professores de português, para o estudo das obras em causa.

No grupo de aplicação do programa, a sequência pedagógica a que se refere o presente estudo teve a duração de três aulas: uma aula ou período inicial dedicada à preparação para leitura do episódio mais alargado que era alvo do trabalho pedagógico e respectiva leitura; uma aula dedicada às atividades de leitura detalhada e de reescrita 
conjunta, com duração de noventa minutos; na terceira aula ou período da sequência, os alunos realizaram a reescrita individual.

Nos Grupos B, o trabalho dedicado ao estudo do episódio repartiu-se por duas aulas e incluiu as atividades de leitura e de questionário de compreensão. Não contemplou a atividade de reescrita conjunta. A reescrita individual, a finalizar, foi solicitada para a recolha de dados, a fim de estabelecer a comparação com a reescrita realizada no âmbito do programa Ler para Aprender.

Para a realização da tarefa de reescrita, os alunos dos dois grupos receberam a mesma instrução, focada no trecho a reescrever. Para a reescrita do excerto de $A$ floresta, era dada a instrução: "Nas últimas aulas, trabalhaste um excerto de $A$ floresta, de Sophia de Mello Breyner: a passagem em que Isabel tem a surpresa de encontrar um anão na casa que tinha construído. Nas linhas abaixo, reescreve essa parte da história, utilizando uma linguagem cuidada e expressiva, para que o teu texto cative o leitor." No caso do sexto ano, a instrução era similar, com as alterações correspondentes para o texto da obra Ulisses, de Maria Alberta Menéres.

Em todos os grupos, para a realização da tarefa, os alunos puderam ter acesso quer à obra quer aos materiais e trabalhos realizados nas atividades anteriores. No caso dos Grupo A, esse acesso colocava o desafio de escrever uma nova versão, que não podia ser uma cópia, quer do texto original, quer da reescrita realizada em conjunto, podendo, no entanto, recorrer a elementos já encontrados nestes momentos e ainda na exploração realizada durante a atividade de leitura detalhada. No caso dos Grupos B, o desafio colocado pela tarefa de reescrita não tinha a referência de versões anteriores, para além do texto original.

Recolhidas as versões escritas pelos alunos na tarefa de reescrita individual, procedeu-se à respectiva análise, tomando como base para a comparação: a extensão da reescrita, considerando o número de palavras, quer na globalidade, quer em relação à passagem correspondente ao excerto em foco; a ocorrência na reescrita de sequências dotadas de maior especificidade, como eventos, descrições e reações. No caso da extensão textual, para verificar o alcance dos eventuais contrastes entre as médias dos dois grupos, procedeu-se à aplicação estatística do teste $t$, para amostras independentes, com recurso ao programa estatístico SPSS, versão 23.

\section{Resultados}

\section{Apresentação dos resultados}

Os resultados correspondentes à extensão dos textos resultantes das reescritas são apresentados na Tabela 1. Inclui-se a indicação da extensão dos excertos originais, para poder ser tomada como referência. 
Tabela 1 - Extensão da reescrita

\begin{tabular}{|c|c|c|c|c|c|c|}
\hline Ano & $\begin{array}{c}\left(\mathrm{N}^{\circ}{ }^{\circ} \text { de palavras do }\right. \\
\text { texto original) }\end{array}$ & Grupos & $\begin{array}{l}\text { Texto global: } \\
\text { Média } \\
\text { (mín. - máx.) }\end{array}$ & Desvio-padrão & $\begin{array}{c}\text { Passagem em foco: } \\
\text { Média } \\
\text { (mín. - máx.) }\end{array}$ & Desvio-padrão \\
\hline \multirow[t]{2}{*}{$5 .^{\circ}$} & \multirow[t]{2}{*}{ (127) } & A & $\begin{array}{c}127 \\
(99-234)\end{array}$ & 25,715 & $\begin{array}{c}126 \\
(99-211)\end{array}$ & 23,639 \\
\hline & & B & $\begin{array}{c}158 \\
(73-272)\end{array}$ & 63,962 & $\begin{array}{c}23 \\
(5-49)\end{array}$ & 11,865 \\
\hline \multirow[t]{2}{*}{$6 .^{\circ}$} & \multirow[t]{2}{*}{ (111) } & $A$ & $\begin{array}{c}126 \\
(82-205)\end{array}$ & 32,007 & $\begin{array}{c}125 \\
(82-195)\end{array}$ & 30,245 \\
\hline & & B & $\begin{array}{c}235 \\
(103-417)\end{array}$ & 67,705 & $\begin{array}{c}58 \\
(28-116)\end{array}$ & 24,439 \\
\hline
\end{tabular}

Fonte: dados da pesquisa.

As médias dos Grupos A encontram-se bastante mais próximas da extensão do excerto original. Contudo, as extensões no conjunto dos alunos estão longe de ser uniformes, em qualquer dos grupos, como mostram os valores mínimos e máximos e os valores do desvio-padrão. Para a extensão global do texto, a comparação mostra uma extensão média superior, no caso dos alunos que não participaram no programa, em relação aos alunos dos Grupos A, quer no quinto (158 vs. 127) quer no sexto ano de escolaridade (235 vs. 126). A diferença entre as médias é considerada estatisticamente significativa, conforme revela o resultado do teste $\mathrm{t}\left(t_{72}=-2,903\right.$, $\mathrm{p}=, 005$, para o quinto ano de escolaridade; $t_{97}=-10,932, \mathrm{p}=, 00 \mathrm{o}$, para o sexto ano de escolaridade).

Os resultados respeitantes à extensão da passagem em foco (os episódios do encontro de Isabel com o anão ou o aparecimento da ideia a Ulisses e a construção do cavalo de madeira) são apresentados na penúltima coluna da tabela. No caso dos alunos que participaram do programa, a reescrita é ocupada quase totalmente com a passagem em foco. No caso dos restantes alunos, a abordagem é diferente: apenas uma pequena parte do texto é dedicada a essa passagem. As diferenças surgem como estatisticamente muito significativas em qualquer dos anos de escolaridade $\left(t_{72}=\right.$ $22,189, \mathrm{p}=, 000$, para o quinto ano; $t_{97}=11,236, \mathrm{p}=, 000$, para o sexto ano). Enquanto os alunos que participaram no programa dedicam uma proporção em torno de 99\% das palavras da reescrita à passagem em foco, no caso dos restantes alunos, essa proporção corresponde apenas a 14\% e 25\% (ver Figuras 1 e 2), respectivamente para o quinto e sexto anos de escolaridade.

Como se mostra nas figuras seguintes, a amplitude da reescrita, no caso dos Grupos B, alarga-se a outros momentos, enquanto permanece focada, no caso dos Grupos A, num momento específico, que foi objeto das atividades. 
Figura 1 - Momentos da história presentes na reescrita ( $5^{\circ}$ ano)

Grupo A - Ler para Aprender

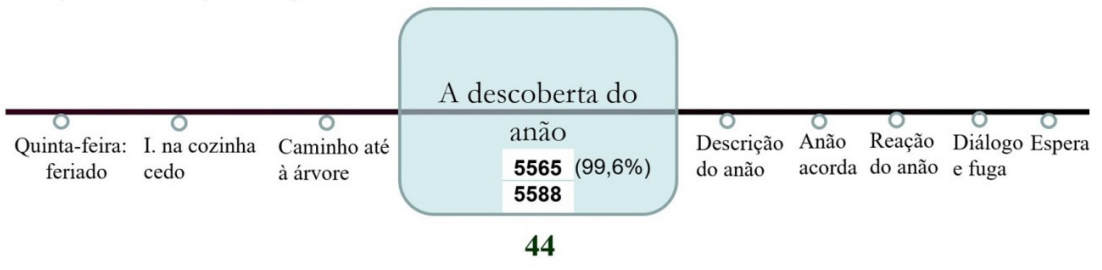

Grupo B - outros alunos

\begin{tabular}{|c|c|c|c|c|c|c|c|c|}
\hline & & & A descoberta & & & & & \\
\hline 0 & 0 & 0 & do anão & $\begin{array}{c}0 \\
\text { Descricão }\end{array}$ & Anão & Reacão & Diálo & Espera \\
\hline Feriado & almoço & à árvore & $680(14 \%)$ & do anão & acorda & do anão & e fuga & \\
\hline & 4 & 2 & 4742 & 14 & 16 & 14 & 28 & 14 \\
\hline
\end{tabular}

30

Fonte: dados da pesquisa.

Os valores acompanhados de percentagem correspondem ao valor absoluto e à proporção referida de palavras do excerto dedicadas ao momento da descoberta do anão, em relação ao total de palavras da reescrita. Os números inscritos por debaixo da designação desse e dos outros momentos correspondem à indicação do número de alunos que inserem esse momento na sua reescrita.

Quer no Grupo A, quer no Grupo B, todos os alunos contemplam o momento em foco (a descoberta do anão). Contudo, no caso do Grupo B, para além do momento em foco, outros momentos ou sequências são contemplados na reescrita dos alunos, designadamente a descrição do anão, o momento em que acorda, a sua reação ao ver Isabel, o diálogo que estabeleceram e a fuga do anão, bem como a espera de Isabel.

0 que observamos na Figura 1, em relação ao quinto ano, encontra paralelismo com o que sucede nas reescritas dos dois grupos, no sexto ano, como se pode observar na Figura 2.

Figura 2 - Momentos da história contemplados na reescrita ( $6^{\circ}$ ano)

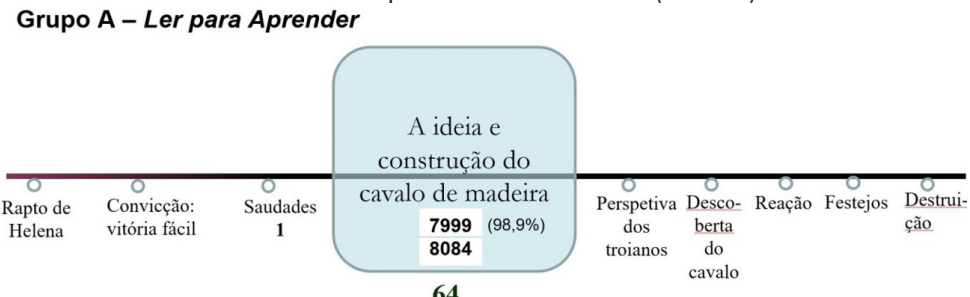

64

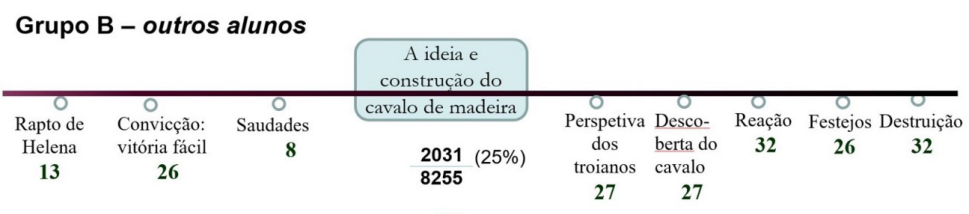

35

Fonte: dados da pesquisa. 
Enquanto no Grupo A os alunos permanecem focados no excerto que foi objeto de trabalho, para a tarefa de reescrita, no caso do Grupo B, um número significativo de alunos estende a reescrita a outros momentos da narrativa, desde o rapto de Helena até à destruição da cidade de Troia, como revelam os valores inscritos por debaixo de cada momento, na Figura 2.

\section{Discussão}

0 estudo realizado emerge da aplicação de um programa pedagógico numa escola. 0 contraste entre grupos de alunos que participaram e não participaram no programa encontra virtualidades pelo fato de se ter realizado na mesma escola. Contudo, não se advoga uma posição de generalização das diferenças encontradas. 0 estudo foi realizado primordialmente para alimentar a reflexão no interior do grupo de formação e da própria escola, acompanhando a aplicação e apreensão de potencialidades das atividades do programa. É essa posição que se defende em relação a novas aplicações em novos contextos: a permanente consciencialização e reflexão com base nos resultados que vão sendo alcançados.

Expressa a ressalva anterior, observa-se que os resultados revelam contrastes significativos, quanto às reescritas realizadas, entre os dois grupos. Esses contrastes remetem-nos para abordagens diferenciadas. No caso dos grupos que não participaram do programa, em qualquer dos anos, a reescrita é entendida como a integração do momento em foco na linha de eventos narrativos que o precedem e que lhe sucedem.

Este alargamento da amplitude focal da reescrita conduz à produção de textos de reescrita, em média, mais extensos, pois alarga-se também o que há a contar. Fazendo uso de linguagem cinematográfica, podemos considerar que estamos perante uma estratégia de zoom out, a partir da qual se recontam os eventos mais relevantes que enquadram o momento em foco.

Em contrapartida, perde-se proximidade em relação à expressão linguístico-textual e de sucessão de ações, descrições e reações, que se encontra, a um nível micro, dentro de cada momento ou evento. Por exemplo, no caso do encontro com o anão, só está presente nos textos deste grupo, de forma generalizada, a revelação de que, dentro da casa que Isabel tinha construído, estava um anão. As referências à chegada junto à árvore, à reação de alegria por vê-la intacta, a descrição da casa, a referência à abertura da porta e às reações de imobilidade, de espanto, de pensar que estava a sonhar (ver excerto textual no Apêndice 1) surgem na reescrita deste grupo de forma muito reduzida.

A tarefa de reescrita surge aos olhos dos alunos deste grupo como uma tarefa de sintese do momento narrativo em foco e dos momentos que o acompanham e que possibilitam a sua compreensão por integração na narrativa. Como foi realçado na reflexão realizada na oficina de formação, sendo uma tarefa legítima, nessa perspectiva de compreensão de um momento na estrutura de eventos da narrativa, esta abordagem fica marcada pelo afastamento em relação à própria linguagem, aos recursos léxicogramaticais mobilizados para a construção do texto - os quais também devem ser alvo de aprendizagem se queremos que os textos trabalhados na leitura constituam modelos para a utilização da linguagem por parte dos alunos nos textos que constroem. 
As estratégias do programa Ler para Aprender colocam em foco também a linguagem, designadamente através da leitura detalhada, que incide sobre palavras e expressões específicas na frase. Em contraste com o movimento de zoom out que referimos, encontramos um movimento de zoom in, de aproximação a essas palavras e expressões da passagem textual que se pretende que o aluno compreenda e passe a dominar, a fim de as poder vir a utilizar nos seus próprios textos. Essa incidência continua a estar presente na atividade de reescrita conjunta. Os segmentos realçados anteriormente continuam em relevo e a incidência transpõe-se para o momento da reescrita individual. Como, da reescrita, não se pretende a obtenção de uma cópia, a colocação em foco dos segmentos é acompanhada, ao longo das atividades, da preocupação de alargamento dos recursos linguísticos.

No momento da realização da tarefa de reescrita individual, os alunos já contavam com os recursos encontrados no texto original, na explicitação realizada na leitura detalhada, na procura de novas propostas de formulação apresentadas e discutidas em interação com o professor, na reescrita conjunta. A análise com base nos textos reescritos não esgota o estudo da reescrita. Há dimensões, como o processo de procura e decisão entre formulações possíveis, que não são captáveis através dos textos finais (pelo contrário, na reescrita conjunta, esse processo emerge na interação com o professor e com os colegas). No entanto, os resultados obtidos dão um contributo importante para o conhecimento da apreensão ou ampliação de recursos linguísticos, no âmbito das atividades realizadas. Esses resultados sustentaram a reflexão sobre as aprendizagens nas sessões conjuntas da oficina de formação.

A reescrita faz apelo à reativação dessas possibilidades encontradas anteriormente e à prossecução da procura de novas possibilidades (BARBEIR0, 2015). Por exemplo, de acordo com o registo das atividades realizadas numa das turmas, em relação ao texto do encontro com o anão, a palavra "intacta", que ocorre na frase "A casa estava intacta", constituiu um dos segmentos em foco na leitura detalhada e depois na reescrita conjunta. Na leitura detalhada, a explicitação semântica da palavra conduziu a explicitações no discurso do professor como "[...] não lhe aconteceu nada”, “[...] estava tudo tal como ela tinha deixado", “[...] ninguém tinha mexido na casa”. Durante a reescrita conjunta, a procura em interação de possibilidades de reescrita conduziu às seguintes possibilidades específicas de reescrita: i) "inteira”, ii) "como a tinha construído antes”, iii) "igual”, iv) "tal e qual", v) "tal como ela a tinha deixado", tendo sido esta a versão adotada pela turma, na reescrita conjunta. Na reescrita individual, os alunos recorreram ao termo original ("intacta") e a formulações já encontradas, mas alguns prosseguiram ainda o movimento de procura e reformulação, através de possibilidades como "tal como ela a tinha deixado", "como a deixou”, "inteira, sem nenhum arranhão", "como nova” etc.

A explicitação realizada pelo professor durante a leitura detalhada e a procura de possibilidades de reescrita realizada em conjunto na turma durante a reescrita conjunta projetam-se para a procura de novas possibilidades realizadas individualmente. 0 papel do professor é importante, pois não se trata apenas de encontrar outras palavras, de dizer por outras palavras ou pelas palavras do aluno. É necessário que o aluno apreenda os níveis de linguagem, de elaboração e sofisticação que os gêneros instauram para estabelecer a 
relação com o leitor, para cumprirem o objetivo sociocomunicativo de envolver o leitor, no caso das histórias ou textos narrativos.

\section{Conclusão}

A tarefa de reescrita encontrou neste estudo dois modos de ser realizada: i) um modo que corresponde grosso modo a um resumo escrito que, neste caso, tratando-se do excerto de uma obra mais alargada, adotou uma perspectiva integradora na narrativa do excerto que estava em foco; ii) um modo que se aproximou dos recursos léxico-gramaticais do texto original, procurando encontrar novas possibilidades de (re)escrita entre os recursos disponibilizados pela língua. 0 primeiro modo foi adotado de forma ampla pelos alunos que não participaram na aplicação do programa Ler para Aprender. 0 segundo modo foi adotado pelos alunos das turmas integradas no programa, em conformidade com as atividades nele realizadas.

Estes dois modos não coincidem quanto às competências e desafios que ativam. No primeiro caso, torna-se saliente a capacidade de apreender e expressar a sequência de eventos mais salientes da narrativa e a relação entre eles. No segundo caso, existe uma aproximação à própria linguagem que é tomada de forma específica, como objeto de decisões e de escolhas em relação aos recursos linguísticos que podem ser utilizados em cada ponto textual.

Os alunos dos níveis de escolaridade aqui em estudo, quinto e sexto anos de escolaridade, como os resultados mostram, são capazes de proceder à reescrita de forma específica, a acompanhar, por meio de paráfrase e reformulação, os recursos linguísticotextuais do texto a reescrever. Para isso, precisam de ser instruídos quanto ao modo de realizar a tarefa, para que não a tomem como uma sintese que apenas necessita de referir os eventos mais relevantes no fio da narrativa.

Os desafios e implicações colocados para o ensino-aprendizagem são precisamente o de basear na leitura dos textos a aprendizagem da escrita, não apenas ao nível macroestrutural, mas também ao nível das decisões léxico-gramaticais. A reescrita de textos pode estabelecer essa ponte entre as duas competências, nos dois níveis. Por sua vez, a proximidade da reescrita em relação ao texto original pode ser objeto de percursos que contemplem diferentes graus de proximidade ou afastamento, desde a paráfrase (cf. BARBEIR0, 2015, 2016), como grau mais próximo e que esteve em relevo neste estudo, passando a graus de maior distanciamento, em variantes nas quais a reescrita assume, desde logo, variação em relação ao texto original, por exemplo, adotando novas personagens, novos acontecimentos, novos contextos, novos problemas ou soluções para a reescrita do texto. A modalidade de reescrita com manutenção do campo do texto original apresenta, por conseguinte, potencialidades também em relação aos textos cujo objetivo é envolver o leitor, como as histórias, e não apenas em relação aos textos factuais.

A reescrita não surge, como mostraram as diferenças encontradas no estudo, de forma automática e única. Ela se constitui como um campo de trabalho pedagógico, em que os instrumentos, as estratégias e atividades adotadas potenciam determinados resultados, de que o professor deve ser consciente, para os integrar na sua prática. 


\section{Referências}

ADAMS, Marilyn. Beginning to read: thinking and learning about print. A summary. Urbana-Champaign: University of Illinois, 1990.

BARBEIRO, Luís Filipe. Paráfrase e reescrita no percurso para a autonomia: que patamar de proximidade textual? In: CARVALHO, José A. Brandão et al. (Org.). SIMPÓSIO INTERNACIONAL DE ENSINO DE LÍNGUA PORTUGUESA (SIELP), 5., 2016, Braga. \& FÓRUM IBER0-AMERICANO DE LITERACIAS (FIAL), 5., 2016, Braga. Atas do... Braga: Universidade do Minho, 2016. p. 74-83.

BARBEIR0, Luís Filipe. Reescrita: domínio e alargamento dos recursos linguísticos. Exedra, Coimbra, n. temático "Didática do Português", p. 209-235, 2015.

BEREITER, Carl; SCARDAMALIA, Marlene. The psychology of written composition. Hillsdale: Lawrence Erlbaum, 1987.

BRUNER, Jerome. Le développement de l'enfant: savoir faire, savoir dire. Paris: PUF, 1983.

COFFIN, Caroline. Teacher learning for European literacy education: final report. The Hague: European Union, 2014.

COSTA, Armanda; VASCONCELOS, Sofia, SOUSA, Vitória. Muitas ideias, um mar de palavras: propostas para 0 ensino da escrita. Lisboa: Fundação Calouste Gulbenkian, 2010.

EMIG, Janet. The web of meaning. Upper Montclair: Boynton/Cook, 1983.

FERREIRA, Elisa, ARAÚJO, Denise. 0 (não) funcionamento da reescrita em textos produzidos por licenciandos em letras. Trabalhos em Lingüística Aplicada, Campinas, v. 53, n. 1, p. 201-224, 2014.

FIAD, Raquel, BARROS, Juliene. 0 papel da intercalação na reescrita. Revista Brasileira de Linguística Aplicada, Belo Horizonte, v. 1, n. 3, p. 9-23, 2003.

FONSECA, Eduardo. Paradigmas, Programas e ensino da língua materna. Revista Portuguesa de Educação, Braga, v. 3, n. 3, p. 51-61, 1990.

GOUVEIA, Carlos. A compreensão leitora como base instrumental do ensino da produção escrita. In: SILVA, Wagner R.; SANTOS, Janete S.; MELO, Márcio A. (Org.). Pesquisas em língua(gem) e demandas do ensino básico. São Paulo: Pontes. 2014. p. 203-231.

HALLIDAY, Michael A. K. Meaning as choice. In: FONTAINE, Lise; BARTLETT, Tom; O'GRADY, Gerard (Ed.). Systemic functional linguistics: exploring choice. Cambridge: Cambridge University Press. 2013. p. 15-36.

HALLIDAY, Michael A. K.; MATTHIESSEN, Christian. Halliday's introduction to functional grammar. London; New York: Routledge, 2014. 
HAYES, John. A new framework for understanding cognition and affect in writing. In: LEVY, C. Michael; RANDALL, Sarah (Ed.). The science of writing: theories, methods, individual differences, and applications. Mahwah: Erlbaum, 1996. p. 1-27.

HAYES, John. Modeling and remodeling writing. Written Communication, Thousand Oaks, v. 29, n. 3, p. 369-388, 2012.

HAYES, John; FLOWER, Linda. Identifying the organization of writing processes. In: GREGG, Lee; STEINBERG, Erwin (Ed.). Cognitive processes in writing. Hillsdale: Erlbaum, 1980. p. 3-30.

HYLAND, Ken. Genre-based pedagogies: a social response to process. Journal of Second Language Writing, Amsterdã, v. 12, n. 1, p. 17-29, Feb. 2003.

LEGROS, Denis; CRINON, Jacques; MARIN, Brigitte. Réécrire et apprendre à réécrire: le rôle d'une base de données textuelles. Langages, Paris, v. 164, p. 98-112, 2006.

MARTIN, James Robert. Mentoring semogenesis: 'genre-based' literacy pedagogy. In: CHRISTIE, Francis. (Ed.). Pedagogy and the shaping of consciousness: linguistic and social processes. London: Continuum, 1999. p. 123-155.

MARTIN, James Robert; ROSE, David. Genre relations: mapping culture. London: Equinox, 2008.

O'DONNELL, Michael. A dynamic view of choice in writing: composition as text evolution. In: FONTAINE, Lise; BARTLETT, Tom; O'GRADY, Gerard (Ed.). Systemic functional linguistics: exploring choice. Cambridge: Cambridge University Press, 2013. p. 247-266.

ROSE, David. Engaging and supporting all our students to read and learn from reading. PETAA Paper, Sydney, v. 202, p. 1-12, 2016b.

ROSE, David. Genre, knowledge and pedagogy in the 'Sydney School'. In: ARTEMEVA, Natasha; FREEDMAN, Aviva (Ed.). Genre studies around the globe. Ottawa: Inkwell, 2015. p. 299-338.

ROSE, David. Languages of schooling: embedding literacy learning with genre-based pedagogy. European Journal of Applied Linguistics, Berlim, v. 6, n. 1, p. 59-89, 2018b.

ROSE, David. New developments in genre-based literacy pedagogy. In: MACARTHUR, Charles A.; GRAHAM, Steve; FITZGERALD, Jill (Ed.). Handbook of writing research. New York: Guilford, 2016a. p. 227-242.

ROSE, David. Pedagogic register analysis: mapping choices in teaching and learning Functional Linguistics, Sun Yat-Sen, v. 5, n. 3, p. 1-33, 2018a.

ROSE, David. Reading to learn: accelerating learning and closing the gap. Sydney: Reading to Learn, 2012.

ROSE, David; ACEVEDO, Claire. Learning to write, reading to learn: background and development of genrebased literacy improvement projects in Australia. Revista Lenguaje y Textos, Cidade Real, v. 46, p. 7-18, 2017. 
ROSE, David; MARTIN, James Robert. Learning to write, reading to learn: genre, knowledge and pedagogy in the Sydney school. London: Equinox, 2012.

SANTOS, Maria do Socorro Ferreira dos; ARAÚJO, Anne Francialy da Costa; CALIL, Eduardo. A reescrita na sala de aula: iniciando uma discussão. Letras de Hoje, Porto Alegre, v. 33, n. 2, p. 213-219, 1998.

SARTORI, Adriane, MENDES, Lucíola. A reescrita como processo: As vantagens de uma segunda versão tardia. Revista do GEL, Assis, v. 13, n. 3, p. 130-157, 2016.

TEBEROSKY, Ana. Compor textos. In: TEBEROSKY, Ana; TOLCHINSKY, Liliana (Org.). Além da alfabetização: a aprendizagem fonológica ortográfica textual e matemática. São Paulo: Ática. 1996. p. 85-117.

VYGOTSKY, Lev S. Pensamento e linguagem. São Paulo: Martins Fontes, 1991.

WILLIAMS, Geoff. Joint book-reading and literacy pedagogy: a socio-semantic examination, CoRE, Valência, v. 19, n. 3, p. F 2B01- F 6B01, 1995.

WILLIAMS, Geoff. The pedagogic device and the production of pedagogic discourse: a case example in ealy literacy education. In: CHRISTIE, Francis (Ed.). Pedagogy and the shaping of consciousness. London; New York: Continuum, 1999. p. 88-122.

\section{Apêndice 1}

Mas quando chegou em frente do velho tronco sorriu de alegria. A casa estava intacta com o telhado de casca de plátano muito bem coberto de musgo e a porta de cana muito bem fechada. E tinha um ar extraordinariamente sossegado e confortável.

Isabel ajoelhou-se no chão e com cuidado abriu a porta.

Aquilo que viu deixou-a imóvel, muda, com a boca aberta, com os olhos esbugalhados e as mãos erguidas e abertas no ar.

Durante alguns momentos o seu espanto foi tão grande que nem se podia mexer, nem podia pensar no que via.

Depois, devagar, esfregou os olhos. Abriu-os muito e murmurou:

- Estou a sonhar!

Pois dentro da casa tinha acontecido uma coisa extraordinária e incrível:

Em cima da cama estava deitado um verdadeiro anão.

ANDRESEN, Sophia de Mello Breyner. A floresta. Porto: Figueirinhas, 2004. p. 15-16.

\section{Apêndice 2}

Então Ulisses, que todos diziam ser o mais manhoso dos homens, pensou, pensou e teve uma ideia: construir um enorme, um gigantesco cavalo de pau, assente num estrado com rodas para se poder deslocar, e dentro do bojo, ou seja, da barriga desse cavalo, se esconderam alguns homens. 
Mas para que seria esse cavalo? Ulisses imaginou que os gregos deviam fingir que iam todos embora dali e deixar às portas de Troia o monumental cavalo sozinho... em ar de homenagem!

Depois de o construírem, assim fizeram. E levantaram as suas tendas de dez anos, cavalos verdadeiros, tudo. A pouco e pouco foram-se retirando e desapareceram ao longe nas colinas, na distância.

MENÉRES, Maria Alberta. Ulisses. 23. ed. Porto: Asa, 1999. p. 12-13.

Recebido em: 09.01.2019

Revisado em: 09.04.2019

Aprovado em: 25.06.2019

Luís Filipe Barbeiro é doutor em educação (Metodologia do Ensino do Português) e agregado em ciências da educação (Literacias e Ensino do Português). É professor coordenador principal da Escola Superior de Educação e Ciências Sociais do Instituto Politécnico de Leiria. A sua investigação foca-se na didática da escrita, língua materna e não materna. 